\title{
¿Qué es un cluster? Geografías y prácticas de la escena de música experimental en Santiago, Chile
}

Manuel Tironi Rodó Instituto de Sociología, Pontificia Universidad Católica de Chile.

RESUMEN | Las teorías sobre la clusterización económica, y en particular sobre la aglomeración geográfica en la industria creativa, asumen una idea de 'lugar' o 'localidad' en extremo estática, autoclausurada e idealizada. A través de evidencia empírica, y después de una revisión de los argumentos a favor y en contra de dicha idea de 'lugar' en la literatura especializada, este artículo explora la escena de música experimental de Santiago, Chile, como caso de una industria creativa estructurada en una espacialidad alternativa. Específicamente, se argumenta que dadas ciertas condiciones productivas, culturales y urbanísticas, las industrias creativas pueden desplegarse en torno a espacialidades múltiples, móviles y eventuales, sin que esto mine los efectos de cluster esperados. Finalmente, y sólo a modo especulativo, se propone una nueva figura espacial para dar cuenta de los procesos de clusterización económica en ciudades emergentes.

PALABRAS CLAVE | Cultura urbana, economía urbana, movilidad, redes.

ABSTRACT | Cluster theories, and particularly theories on creative clustering, have assumed a highly static, self-contained and idealized idea of the 'local'. Based on empirical evidence, and following a review of the arguments in favor and against this idea of the 'local', the article explores the experimental music scene in Santiago de Chile, as a case of a creative industry structured around an alternative spatiality. Specifically, we argue that under certain productive, cultural and urban conditions, creative industries can unfold around multiple, mobile and eventual spatialities without losing the expected cluster effeects. Finally, and only speculatively, we propose a new spatial structure for understanding the process of economic clustering in developing cities.

KEY WORDS | Urban culture, urban economy, mobility, networks.

Recibido el 27 de enero de 2010, aprobado el 21 de septiembre de 2010.

Correspondencia: Manuel Tironi Rodó, Instituto de Sociología, Pontificia Universidad Católica de Chile. Av. Vicuña Mackenna 4860, Campus San Joaquín, Macul, Santiago. Fono: (562) 3545146; E-mail: metironi@uc.cl 


\section{Introducción}

El modelo de la llamada "ciudad creativa" se expande. Como dice Peck (2005), "de Singapur a Londres, de Dublín a Auckland, de Memphis a Amsterdam; sin más, hasta Providence, RI y Green Bay, WI”, toda ciudad quiere convertirse en una. Pero a pesar de su popularización, la expansión de la ciudad creativa como modelo de desarrollo urbano ha gatillado varios cuestionamientos. Algunos (Healy, 2002; Glaeser 2004) han apuntado hacia las debilidades metodológicas del modelo, especialmente al formulado por Florida (2002 y 2005). Otros (Donald y Morrow, 2003) han reprochado la escasa reflexión en materia de política pública que dicho modelo desarrolla, mientras que varios académicos (Peck, 2005; Markusen, 2006; Fougère y Solitander, 2007; Sabaté y Tironi, 2008) critican las implicancias político-ideológicas que moviliza la noción de 'ciudad creativa'.

Pero el modelo 'creativo' también posee un flanco conceptual altamente problemático que aún no ha sido lo suficientemente interrogado. Desde una perspectiva analítica, la característica más relevante de dicho modelo es que radicaliza la noción de cluster: lleva al extremo la idea según la cual la proximidad física e institucional trae beneficios productivos y propulsa la innovación. Así, el modelo da un paso más -y tal vez el definitivo- en la tendencia iniciada por la escuela de los milieux innovateurs de incrustar las economías localizadas en la textura urbana y cultural de sus territorios. Dicho de otro modo, la propuesta de Florida puede ser vista como la celebración non plus ultra de lo local: un modelo de desarrollo económico en el cual lo "local" deja de ser un aspecto abstracto, institucional y/o funcional -como es el caso en todos los modelos de innovación territorial (Moulaert y Sekia, 2003) - para convertirse en una localidad en el sentido sociológico más tradicional del término: como un lugar, como una situación espacial delimitada, fija, morfológicamente constituida a partir de elementos concretos y singulares y estructurada en la copresencia y en los significados colectivamente compartidos.

Pero esta noción de lo local puede, y debe, ser revisada. Ya no queda tan claro que la idea sociológica de una localidad entendida como un lugar cerrado, estático y próximo pueda ser sostenida en vistas de los cambios experimentados por la ciudad y la cultura urbana. Las nuevas tecnologías, las cada vez más oblicuas infraestructuras de transporte y el énfasis en las prácticas culturales de los agentes urbanos obligan que la noción de 'espacio' ceda a la idea de espacialidades (Amin, 2002; Law y Hetherington, 2000): de situaciones espaciales que son múltiples, heterogéneas y abiertas a distintas configuraciones espacio-temporales.

En base a lo anterior, el objetivo de este artículo es cuestionar la noción de cluster y de localidad que ésta moviliza a partir de un caso de economía creativa en Santiago de Chile. Se busca, asimismo, proponer una forma alternativa de aproximarse a las economías localizadas, especialmente a las del sector cultural/creativo, prescindiendo de los supuestos ontológicos del lugar que pueden ser pertinentes para ciertas ciudades de países desarrollados, pero que hacen poco sentido en la actual realidad urbana de sociedades emergentes. Esta propuesta se fundamentará en el caso de la escena de música 
experimental de Santiago, una protoindustria que, como se verá, es altamente innovadora y productiva a pesar de no poseer una territorialidad acorde con lo que la literatura de los clusters en general -y de la ciudad creativa en particular- imponen como condición de base. Al ser un caso específico, no se pretenden generalizar sus particularidades. Sin embargo, creemos que las interrogantes epistemológicas y conceptuales que este caso abre son de alta relevancia para ciudades emergentes como Santiago, que buscarán implementar -si no lo están haciendo ya- políticas urbanas "creativas" que se verán frustradas si no son capaces de identificar cuáles son las lógicas territoriales, organizacionales y culturales que animan los procesos de producción situada.

La estructura del artículo se organiza en cuatro secciones. En la primera se expondrá la genealogía del modelo de la ciudad creativa, argumentando que éste puede verse como el punto culmine del llamado "nuevo localismo" (Amin y Thrift, 2002). En la segunda sección se revisarán brevemente las críticas que desde la geografía económica, la sociología urbana y los estudios en ciencia y tecnología se han elaborado contra este "nuevo localismo" y sus supuestos asociados. En la tercera sección se presentará el estudio de caso y sus principales resultados, para concluir en una cuarta sección con algunas consideraciones finales.

\section{El nuevo localismo, clusters y ciudad creativa: la fuerza del 'estar ahí'}

\section{Los orígenes: el legado de Marshall}

Si bien las ideas de aglomeración y economía de urbanización ya habían sido avanzadas por von Thünen (1826), Ricardo (1817) y, muy especialmente, por Marshall (1881), hubo que esperar hasta la década de 1980 para que los principios desarrollados por la economía urbana y regional se fusionaran con las reflexiones provenientes de la geografía económica ${ }^{1}$. En efecto, los primeros pasos dados a mediados del siglo pasado, bajo el concepto de las economías de aglomeración, aún concebían a la ciudad como un espacio abstracto y funcional (ver Hirsch, 1973). No fue hasta fines de los 1980s que algunos economistas como Krugman (1991), Porter (1998) y Piore y Sabel (1984), reconociendo los avances de la geografía económica, redescubrieron el poder de lo local, otorgándole a la ciudad mayor textura y complejidad en sus explicaciones económicas. Dada la novedad y el impacto que supuso esta fusión disciplinar, algunos autores no dudaron en catalogarla como una "convergencia de paradigmas" (Vásquez-Barquero, 2006; Trullén, 2006) o como el nacimiento de una "nueva geografía económica" (Amin y Thrift, 2002; Krugman, 1991; Trullén, 2006).

1 La preocupación por la economía urbana, es decir, por los funcionamientos económicos de las metrópolis, data al menos de la década de 1960. Los trabajos de Albert Hirschman, Nicholas Kaldor, François Perroux y Gunnar Myrdal desde la economía son un ejemplo. También lo son los seminales trabajos de Harvey (1973), Castells (1979 [1972]) y, probablemente los más importantes, de Lefebvre (2003 [1970]). En estos trabajos ya se discute la importancia del capital en la configuración de lo urbano y también, en el caso de Lefebvre, de la ciudad en la constitución del capitalismo. Pero el vínculo entre economía y ciudad o era enteramente marxista (la ciudad como epifenómeno del capital, léase Harvey y Castells), puramente funcional (la ciudad maximiza las economías de escala, léase los economistas urbanos), o exclusivamente cultural (la ciudad crea la disposición hacia el capitalismo, Lefebvre). La novedad de los años 1980 es que a una pregunta funcionalista-económica (cómo se crea riqueza en la ciudad) se da una respuesta urbanística (por las características específicas de la ciudad). 
A grandes rasgos, una serie de investigaciones mostraban que en una economía globalizada y ante mercados altamente segmentados, las empresas tienen que recurrir a sus entornos directos en la búsqueda de ventajas competitivas. Y estas ventajas competitivas sólo pueden aumentar si varias empresas del mismo sector, especializadas en distintas fases del proceso productivo, comienzan a generar redes entre ellas y entre esta aglomeración y los demás agentes locales (instituciones políticas, comunidad local, otros actores económicos, etc.). Las guías teóricas están, de nuevo, en las reflexiones pioneras de Alfred Marshall sobre los distritos industriales (Bathelt et al., 2004; Camagni, 2005; Malberg y Maskell, 2002). Este economista fue el primero en enfatizar la importancia de las ecologías locales en la producción industrial (Becattini, 2002). De estas nociones comienza a surgir una serie de modelos territoriales que buscaban entender (y propulsar) las formas espacio-institucionales que mejor desplegaban la innovación y la producción económica. Los distritos industriales, milieux innovateurs, sistemas de producción localizada y de innovación regional, los new industrial spaces, la learning region y los clusters -concepto que es utilizado genéricamente para referirse a los modelos de innovación territorial- son algunas de estas fórmulas (Moulaert y Sekia, 2003; Camagni y Maillat, 2006). A pesar de sus diferencias, en el núcleo de éstas se encuentra siempre lo que Marshall (1881) llamaba "atmósfera industrial", o lo que Storper y Venable (2006) denominan el "buzz" y Gertler (2003) el "estar ahí": la idea de que la proximidad espacial ayuda a fomentar el conocimiento tácito, es decir, ese tipo de conocimiento informal, voluble, práctico y que sólo puede formarse en la copresencia e interaccionalmente, y que define la innovación y la ventaja competitiva en una economía global donde el conocimiento formal y codificado se ha vuelto un commodity (Gertler, 2003).

Con este renovado interés por el "estar ahí" nacía un nuevo localismo (Amin y Thrift, 2002) que redoblaba su énfasis en lo local. Lo local (la región, la ciudad) se volvía el pivote de la innovación productiva.

\section{La ciudad creativa: la radicalización de lo urbano}

El modelo de la ciudad creativa puede ser visto como la última fase en el proceso de urbanización -o incorporación de lo urbano- en la reflexión sobre las relaciones entre territorio y economía. A fines de la década de 1990 comienzan a surgir nuevas voces entre geógrafos, arquitectos, urbanistas y economistas que apelaban a una noción de localidad aún más "lugarizada”, esto es, aún más cualitativa, significada y compleja. Se revitalizaba la visión de Jacobs (1968) sobre la constitución vivida, multidimensional y semicaótica del barrio y su importancia para las economías urbanas.

Este giro se consolidó con la hipótesis de Richard Florida sobre la "ciudad creativa" (2002 y 2005). Su libro The rise of the creative class (2002) marcó una nueva etapa en la idea del barrio como fuente de innovación y producción económica. El punto de partida de Florida es que, tal como ya varios estudiosos venían diciendo desde los años 1970, el motor de la nueva economía postindustrial ya no se encuentra en el sector terciario, sino en el creativo. Esto se evidencia, para Florida, en la meteórica expansión de un nuevo grupo laboral, la clase creativa. Florida define como "clase creativa" a aquel 
grupo ocupacional que "agrega valor económico a través de su creatividad" (p. 68) y que según sus cálculos se ha convertido en el propulsor de la economía actual.

Pero lo fundamental está en la relación entre la "clase creativa", ciudad y actividad económica. Florida indica que esta "clase creativa" comparte una misma caracterización sociocultural. Se trata, a grandes rasgos, de las mismas características que definen a la llamada nueva clase media (Du Gay, 1998; Du Gay y Pryke, 2002; Featherstone, 1991; Jackson y Thrift, 1995): individualismo, alta capacidad de consumo, ansias de distinción cultural, alta movilidad y debilidad por la novedad y lo auténtico. Florida descubre que este grupo prioriza trabajar en ciudades que sintonicen con sus estilos de vida por sobre los potenciales beneficios económicos directos que les puede traer un trabajo. Florida da un paso más e identifica cuáles son las tres características básica que una ciudad debe tener para ser atractiva a los ojos de la "clase creativa": poseer un mercado de trabajo "grueso" donde existan muchas alternativas y posibilidades de empleos creativos; alta calidad en equipamiento (lugares donde exista calidad de vida, desde parques hasta un buen sistema educacional) y, sobre todo, densidad y dinamismo cultural. Este último punto debe ser resaltado. Florida insiste que, para la clase creativa, 'cultura' no significa teatros de ópera o museos, sino el tipo de efervescencia y vitalidad que emerge en ciertos lugares particulares: espacios ricos en vida barrial, en actividades culturales, en patrimonio y en autenticidad y tolerancia.

Es importante enfatizar el concepto de "lugar" que emerge. A diferencia de la economía urbana tradicional que veía a la ciudad con un espacio genérico, en el "nuevo localismo" -y especialmente en la teoría de la "ciudad creativa"- aparece una idea de lugar mucho más cercana a la triple definición de Agnew (1987): el "lugar" como una situación geocultural que se ensambla en base a una locación (ubicación geográfica definida), una localidad (el espacio concreto en el que se desenvuelven las relaciones sociales), y un sentido de lugar (el vínculo subjetivo y emocional que se tiene con el lugar). La idea del "estar ahí" ya indica un lugar en el sentido de Agnew (sólo se puede dar esa interpenetración tácita si hay un mundo-de-la-vida compartido). La teoría de la "clase creativa", no obstante, refuerza esta idea: hace explícito el valor económico de los lugares, en oposición a los espacios banales e intercambiables de la globalización (Muñoz, 2008). No es gratuito, por tanto, que la imaginería en torno a la ciudad creativa orbite siempre en torno a la figura del $b a-$ rrio bohemio (Lloyd, 2004 y 2006; Tironi, 2009), lugares donde no sólo se aglomera la "clase creativa", sino también donde ésta nace, pues es ahí -y sólo ahí- donde se dan todas las condiciones para que ella se incube: vitalidad, cultura, vida de calle, originalidad. Tampoco sorprende, concordantemente, que la inmensa mayoría de la investigación empírica sobre la ciudad creativa se enfoque en barrios de este tipo (ver, por ejemplo, Crewe, 1996; Crewe y Beaverstock, 1998; Indergaard, 2003 y 2009; Hutton, 2006; Lloyd, 2004 y 2006; Sabaté y Tironi, 2008; Catungal, Leslie y Hii, 2009; Pratt, 2009; Waitt y Gibson, 2009; Lewis y Donald, 2010).

La conclusión de Florida es, entonces, radical: si la clave para el desarrollo económico en la sociedad global está en el capital humano avanzado, es menester, entonces, contar con ciudades ricas en barrios, distritos o clusters urbanos que posean 
las características necesarias para atraer y retener a ese capital. Así, ya no se trata sólo de entender lo local de forma más histórica y multidimensional como lo hizo el "nuevo localismo", sino de acotarlo geográficamente, dotarlo de especificidad urbanística y darle contornos morfológicos: sería sólo en ciertas configuraciones urbanísticas donde el "estar ahí" creativo tendría más posibilidades de incubarse y expandirse. Aun más. No se trata de cualquier tipo de barrio, sino de unos con características muy definidas. Tironi (2008) ha demostrado que los casos emblemáticos del modelo creativo comparten siempre cuatro características: barrios patrimoniales, en situación (urbana y social) transicional, ubicados en sectores céntricos y ricos en cultura de calle. En otras palabras, el modelo de la ciudad creativa se sustenta en una visión en extremo particular del barrio, aquella del barrio angloeuropeo, con fuerte identidad urbana, abundante en patrimonio pero lo suficientemente en declive como para desplegar una vida barrial auténtica y dinámica.

\section{Redefiniendo el espacio de la copresencia}

El giro del modelo creativo, entonces, avanza en una comprensión más rica urbanísticamente de las economías localizadas: dota de lugar a la geografía económica, esto es, de sustancia sociológica y urbanística; la clusterización productiva ya no trata sólo de aglomeraciones de firmas e instituciones, sino de localidades específicas, con entornos urbanos determinados e identidades culturales asentadas (y representadas) morfológicamente. Pero este giro también abre cuestionamientos. Tal vez, el más fuerte es si en la ciudad contemporánea la fórmula urbanística del modelo creativo no apela a ontologías en extremo moderno-ilustrada. Cabe preguntarse, en otras palabras, sino no se está apelando a un tipo de espacialidad en extremo idealizada y, por tanto, estática de lo local.

Es interesante notar que en América Latina -donde podrían haber surgido perspectivas más críticas en base a la larga crítica sociológica ya existente en torno a las particularidades de la modernidad latinoamericana (ver Morandé, 1984) - la literatura especializada tiende a reproducir las ideas convencionales de la geografía económica. Existen interesantes trabajos sobre formación de clusters en la región (Cunha y Aricó, 2001; Gago et al., 2007; Fernández, 2008; Tigre y Silveira, 2009; Mochi, 2009; Ramos, 1998; Silva y Simões, 2004), pero en general se limitan a ocupar sin mayor problematización las nociones de localidad, proximidad y lugar que las teorías de cluster movilizan. Por esta razón, la crítica a esta noción estática y clausurada de lo local no hay que buscarla, al parecer, en algún tipo de "latinoamericanismo" geográfico, sino en las contestaciones que se han realizado desde la sociología, antropología, estudios urbanos y, especialmente, desde la geografía. En lo que sigue se reseñan los cuestionamientos epistemológicos y conceptuales que se han realizado, precisamente desde la geografía, en torno a la definición espacial que moviliza el modelo creativo y, en general, los modelos derivados del "nuevo localismo". 


\section{Local en lo global, global en lo local}

La primera dimensión de la crítica dice relación con el poco reconocimiento que estos modelos hacen de las conexiones globales en la constitución de lo local. En otras palabras, se trata de una crítica a la reificación de lo local como fenómeno "puro". Bathelt et al. (2004) argumentan que la literatura sobre clusterización económica y producción de conocimiento se basa en el supuesto de que el "estar ahí" esa forma de conocimiento clave en la nueva economía sigue una lógica imperturbable de distribución espacial. Se asume que "local = tácito" mientras que "global = codificado" (Bathelt et al., 2004, p. 32); esto es, que el conocimiento informal, práctico y voluble sólo puede formarse y distribuirse cara-a-cara, de ahí que la proximidad sea el objetivo final de los modelos de innovación territorial en su búsqueda por crear una "atmósfera industrial". No obstante, son varios los estudios que han cuestionado dichas presunciones, demostrando que el conocimiento tácito puede producirse en una diversidad de situaciones locales-globales. Por ejemplo, Owen-Smith y Powell (2002) indican que al menos en el caso de la industria biotecnológica de Boston, la generación de conocimiento se lleva a cabo tanto a nivel intracluster como en redes entre distintos clusters. En su análisis de la industria de la publicidad en Londres, Grabher (2001) muestra que la creatividad surge de equipos multidepartamentales operando desde diversas localidades. Asimismo, varios estudios han concluido que la sobredependencia en relaciones locales puede ser dañina para los clusters. Uzzi (1997) indica que la excesiva cercanía o sobreaglomeración de proveedores y clientes puede derivar en redes productivas disfuncionales, mientras que Kern (1996, en Bathelt et al., 2004) señala que los clusters necesitan mantener abiertas las válvulas de información con el exterior para evitar dependencias trayectoriales (path dependence) y encerramientos (lock-in).

El modelo de la ciudad creativa también ha sido cuestionado en esta perspectiva. Slater y Ariztía (2009), en su estudio sobre las políticas creativas propulsadas por Avilés, España, muestran que la "cultura" de esta ciudad -cultura que quiere ser elevada como motor económico- se construye como un ensamblaje en el cual es imposible separar los elementos locales de los globales.

Por último, desde una perspectiva política, resalta el trabajo de Fernández y Vigil (2007), una excepción en el contexto latinoamericano que tiende a utilizar acríticamente la noción de cluster y localidad. Estos autores indican que la literatura reinante asume a los clusters como "nodos territorialmente delimitados, que operan como estructuras cerradas, soldadas, homogeneizadas y dinamizadas por las cooperación intralocal” (p. 873), lo que sería “altamente funcional para argumentar la disolución del Estado nacional” (p. 878). La preocupación central de Fernández y Vigil está en una ideología neoliberal a la que no le convendría reconocer a los territorios - para olvidarse de "las coberturas sociales universalistas del keynesianismo que demandan alta implicación del Estado nacional” (p. 881)- como entidades hechas en base a relaciones multiescalares globales-locales, y no sólo endógenas, entre distintos actores económicos. 
En definitiva, lo local existe, pero no debe ser elevado al estatus de condición sine qua non: lo local está siempre entreverado con lo global, y es sólo en la interacción entre ambas escalas que emerge el (tan deseado) conocimiento tácito y las gobernanzas de los territorios.

\section{Comunidades epistémicas}

Los modelos de innovación territorial asumen que la copresencialidad -desplegada en lugares con características urbanas particulares, añade el modelo creativo- es condición de posibilidad para crear conocimiento. Pero son cada vez más las voces que discuten dicho supuesto.

El "nuevo localismo" hizo suyo por mucho tiempo el concepto de "comunidades de práctica” elaborado por Brown y Duguid (1991; ver también Wenger, 1998) para explicar el proceso a través del cual se crea conocimiento dentro de una firma. Según este concepto, la interacción cotidiana entre agentes orientados hacia la solución de problemas crea mundos-de-la-vida compartidos - colaboraciones cruzadas, informaciones colectivas, repertorios comunes de sentido- que permiten desarrollar actitudes, rutinas, convenciones y arreglos institucionales altamente cohesivos. Los clusters son vistos como catalizadores de estas comunidades, dado que ellos crearían las mejores condiciones, a través de la cercanía y copresencialidad, para promover la interacción y coordinación.

Pero la idea de comunidades de práctica está siendo cuestionada. Amin y Cohendet (2004) señalan que los avances tecnológicos y las nuevas posibilidades móviles están transformando las prácticas organizacionales. En particular, indican que esos mundos-de-la-vida compartidos y esos conocimientos tácitos, con todos sus beneficios productivos, se producen es espacialidades que ya pueden prescindir de la copresencia. O mejor dicho, que la copresencia es una situación que admite múltiples sustratos espaciales. Los foros on-line, las tecnologías móviles, las videoconferencias, correos electrónicos y, también, la proliferación de espacios diseñados espacialmente para encuentros temporales - en hoteles y/o aeropuertos-son utilizados para crear coordinaciones, interacciones y confianzas -en fin, conocimiento tácito- de formas que no echan mano al cara-a-cara, al menos en su forma tradicional (Grabher, 2001; Maskell et al., 2004. Ver también Urry, 2000). En particular, se habla de un conocimiento que se forma en comunidades epistémicas (Knorr-Cetina, 1999), esto es, en comunidades en las cuales lo que se mantiene fijo como ancla del "estar ahí" no es el lugar, sino el conocimiento: comunidades en las cuales sus miembros pueden estar distribuidos geográficamente sin que esto dañe la generación de conocimiento tácito, ya que es éste el que circula generando vínculos, interacciones y rutinas. Se trata, así, de un ataque frontal a la idealización del espacio convencional -y de la aglomeración de agentes, firmas e instituciones en él- como base de la innovación. El espacio local, en su sentido más tradicional, sigue importando en la constitución de economías localizadas, pero ya no puede sostenerse como el único espacio que permite la incubación y difusión de conocimiento tácito. 


\section{Geografias prácticas}

Por último, y desde una perspectiva más cultural, la geografía económica ha comenzado progresivamente a reconocer que el espacio no es una entidad dada en el orden de lo natural, es decir, un fenómeno objetivo, homogéneo y unitario. Por el contrario, se empieza a entender el espacio como un fenómeno construido, por tanto relacional y múltiple (Massey, 2005). Tal vez el último asalto en esta dirección ha sido comprender que el espacio se hace en la práctica. El espacio deja de ser asumido como una causa, para ser leído como un efecto: el espacio se construye y es un producto que debe ser explicado en la acción concreta y situada de los actores que lo usan (Amin y Thrift, 2002; Law, 2000). Se empieza a hablar, por ejemplo, de la performatividad de la geografía para referirse a un espacio que lejos de ser un a priori se hace corpórea (Thrift, 1996) y situacionalmente (Tironi, 2009). Ibert (2010) muestra que la distancia/proximidad interaccional entre actores de la industria de la biotecnología se construye in situ y a partir de una diversidad de elementos, incluyendo prácticas corporalizadas de los propios agentes.

Si el espacio es una construcción práctica, entonces importa más cómo los agentes ensamblan distintas espacialidades/localidades que el espacio en sí. El espacio, entonces, deja de ser función de las delimitaciones geográficas y las medidas cartesianas de distancia (Murdoch, 2006). La geografía del Silicon Valley está determinada por la concentración de firmas e individuos en un territorio particular, pero también de las extensas redes de migración e investigación entre California y el Sudeste asiático (Saxenian, 2006). Latham y McCormack (2009) señalan que el entrecruzamiento de elementos de todo tipo -humanos, objetuales, geográficos, ideológicos- en la realización de maratones urbanas hace imposible hablar de ellas como un "fenómeno urbano", siendo preferible entenderlas como unos híbridos locales, globales y translocales. Esto significa que cuando el foco se pone en las tácticas y estrategias que los actores despliegan para crear lugares, se pulveriza la idea de un espacio delimitado y estático, y empiezan a aparecer una multiplicidad de posibilidades espaciales. De hecho, varios autores (Murdoch, 2006; Law, 2000) prefieren hablar de topologías -en contraste con la visión topográfica tradicional- para referirse a la diversidad de formas que el espacio puede asumir, incluso al unísono.

En definitiva, estos tres ataques obligan a pensar el espacio como una entidad inestable, dinámica, heterogénea, práctica y que se hace-haciendo. Asumir que los clusters requieren para crear un "estar ahí" de un espacio estático, delimitado cartesiana y morfológicamente, autoclausurado y -con el modelo creativo- que sigue las características urbanísticas propias de la ciudad angloeuropea convencional es, hoy por hoy, un supuesto altamente cuestionable. En lo que sigue, intentaremos confirmar empíricamente este punto a través de un estudio de caso particular. 
Eventualidad y enactamientos: el caso de la escena de música experimental de Santiago, Chile

\section{Metodología y caso de estudio}

El estudio fue realizado entre enero de 2007 y marzo del 2008 y buscó explorar las lógicas espaciales y organizacionales de la escena de música experimental de Santiago de Chile (EME). La opción por este caso responde a tres características de éste:

- Alta innovación: la EME se desmarca de la industria de la música independiente tradicional al buscar explícitamente traspasar los límites de (a) las sonoridades, (b) los modos de registro y (c) las formas de distribución musical. Por estas razones la EME es una industria de escaso impacto y/o visibilidad mainstream, tratándose de una escena que ejemplifica a cabalidad la "voluntad de frontera" que caracteriza a los procesos de alta innovación.

- Cluster creativo: a pesar de su invisibilidad para la industria oficial, se trata de una escena que ha logrado constituirse como una industria activa y dinámica. Si bien sus retornos son más en capital simbólico y estatutario que en económico -como es por lo demás típico en las industrias culturales emergentes (Markusen, 2006) - ha logrado consolidar un circuito productivo en base a presentaciones, eventos, ferias y talleres. Además, la EME tiene todas las características funcionales del cluster al estructurar su ecología productiva en (a) relaciones horizontales y verticales (Richardson, 1972), al generar (b) derramamientos (spillovers) bajo la forma de netlabels y medios on-line de difusión (Audretsch y Feldman, 2003), y produciendo con lo anterior (c) altos niveles de valor agregado.

- Valor agregado: a pesar de su condición underground y de ser una industria pequeña en relación a otras ciudades del mundo desarrollado, se trata de una escena que ha sido reconocida internacionalmente por su calidad y creatividad, convirtiéndose en una de las pocas industrias chilenas de alto valor agregado celebradas fuera del país. Es importante resaltar este punto: la EME puede resultar marginal en términos económicos e invisible para las políticas públicas y la cultura oficial, pero tiene efectos multiplicativos -y en nichos de punta- que pocas industrias chilenas poseen. La revista Rolling Stone de Argentina y la revista Plan B Magazine de Estados Unidos, The Village Voice de Nueva York y el periódico The Age de Australia son algunos de los medios internacionales que han destacado la emergencia de una escena altamente innovadora en un país latinoamericano fuera del circuito de la avant-garde. De hecho, The Age cataloga la EME entre las "Nicest Surprices '06" (las mejores sorpresas de 2006). El medio australiano comenta que, efectivamente, una de las mejores sorpresas de ese año fue "Discovering an incredibly exciting, self-contained scene in Santiago - Gepe, Javiera Mena, Prissa, Julia Rose, World Music-that may just make Chile the 'New Sweden"' (Carew, 2006). 
El universo total de esta industria alcanza unos 30 proyectos. En base a este universo se llevó a cabo un estudio cualitativo que se estructuró en torno a cinco instrumentos principales. Primero, una encuesta on-line a 20 proyectos para conocer patrones de localización y asociatividad productiva en la EME. Segundo, entrevistas en profundidad a uno o más integrantes de cada uno de los 30 proyectos para conocer la historia productiva y las estrategias organizacionales de los proyectos. Tercero, observaciones etnográficas para registrar las prácticas y discursos de la escena. Cuarto, la aplicación de diarios espacio-temporales con siete proyectos para conocer las lógicas de movilidad. Y quinto, confección de cartografías en base a la información espacial recolectada con los instrumentos anteriores. En lo que sigue mostraremos los principales resultados.

\section{Dispersión y multiplicidad}

Las actividades de la EME no están concentradas espacialmente. No hay nada como un "barrio" o "distrito" que pueda caracterizar la relación físico-espacial entre los diferentes actores de la escena.

La Figura 1 muestra tres espacios clave para la EME y para la producción artística en general (Lloyd, 2006): los espacios de socialización (bares, restaurantes y locales de música en vivo donde los miembros de la escena se reúnen informalmente para intercambiar información, conversar y "chequear" a la competencia), de ejecución (donde la EME se despliega públicamente o donde "toca"), de producción (las salas de ensayo, donde la EME diseña y produce la materia de la escena, su música). Estos tres espacios son lo que Maillat y Camagni (2006) llaman los "espacios de soporte" de un milieu, y que según la teoría de los clusters deberían conformar un mesoespacio cohesionado y geográficamente determinado (Giuliani y Bell, 2004) que propicia el flujo de información y cooperación y la creación de un ambiente industrial (O’Connor, 2006).

FIgURA 1 | Espacios de soporte de la EME

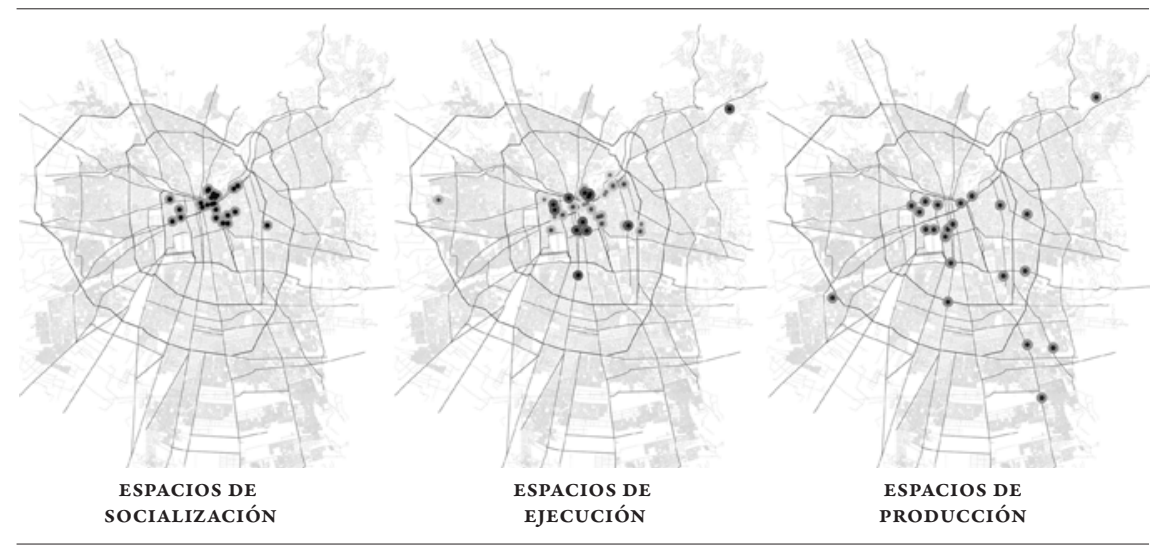

FUENTE ELABORACIÓN PROPIA. 
Y de hecho, la EME muestra signos de aglomeración en torno a la zona céntrica de la capital, pero sólo para los espacios de socialización y ejecución. Los espacios de producción, lejos de estar concentrados en esta área, están esparcidos por toda el área metropolitana. Es posible decir, entonces, que el consumo está dislocado de la producción: los espacios donde se hace el objeto de la EME no calzan con aquellos donde este objeto se muestra o donde sus productores se recrean.

La razón de esta asincronía tiene que ser buscada en dos factores interrelacionados. Primero, que la mayoría de los miembros de la EME siguen viviendo -y ensayando- en sus casas paternas. La EME, entonces, invierte el canon convencional de la geografía de las vanguardias: en vez de quebrar con el "modo de vida pequeño burgués” - propio de sus padres- colonizando espacios urbanos marginales (Deutch y Ryan, 1988; Ley, 2003; Lloyd, 2006), incrustan su producción en el espacio social y físico más convencional de todos: el espacio de la familia. Como lo pone Dadalu, de Colectivo Etéreo, esta situación deriva en un entorno productivo en el cual es imposible separar lo doméstico de lo productivo y cultural:

Ahora ensayamos en la casa de CO2 [dj de Colectivo Etéreo], en Las Condes, porque ahí tienen sus tornamesas y ensayamos en el living. Antes vivía sólo con su papá y tenía una pieza independiente con sus tornamesas. Pero ahora llegó su hermano a vivir con ellos, así que tuvimos que irnos al living.

Y no es que los miembros de la EME quieran ensayar o vivir donde sus padres: es que no pueden hacerlo de otra forma. Así, nos enfrentamos también a una escena altamente precaria que no tiene la capacidad económica o el apoyo institucional para generar un milieu creativo. La escena no se ha apropiado de un espacio como Hackney y Shortdith en Londres, Le Marais en París, Prenzlauer Berg y Wedding en Berlín, Poblenou en Barcelona, Williamsburg en Nueva York o Palermo 'Hollywood' en Buenos Aires- en el cual las disposiciones estéticas de los artistas sean performateadas y sus espacios de trabajo/residencia o producción/ consumo integrados.

La principal característica geográfica de la EME, entonces, es su multipivotalidad y descentramiento: la escena se ordena en al menos dos capas geográficas, una relativamente concentrada y asociada a los espacios "oficiales" de la cultura de Santiago y, la otra, distribuida por el territorio metropolitano sin un foco claro.

\section{Movilidad y temporalidad}

Los espacios de la EME no son sólo múltiples y dislocados, sino también móviles. De hecho, la escena se constituye en -y se despliega a través de- una red de lugares, espacios y locales que están en constante movimiento. Así que incluso si algunas actividades de la EME pueden estar concentradas en ciertas zonas de la ciudad, dentro de esta delimitación su espacialidad es temporal y contingente. 
FIGURA 2 | Localización temporal de espacios de ejecución

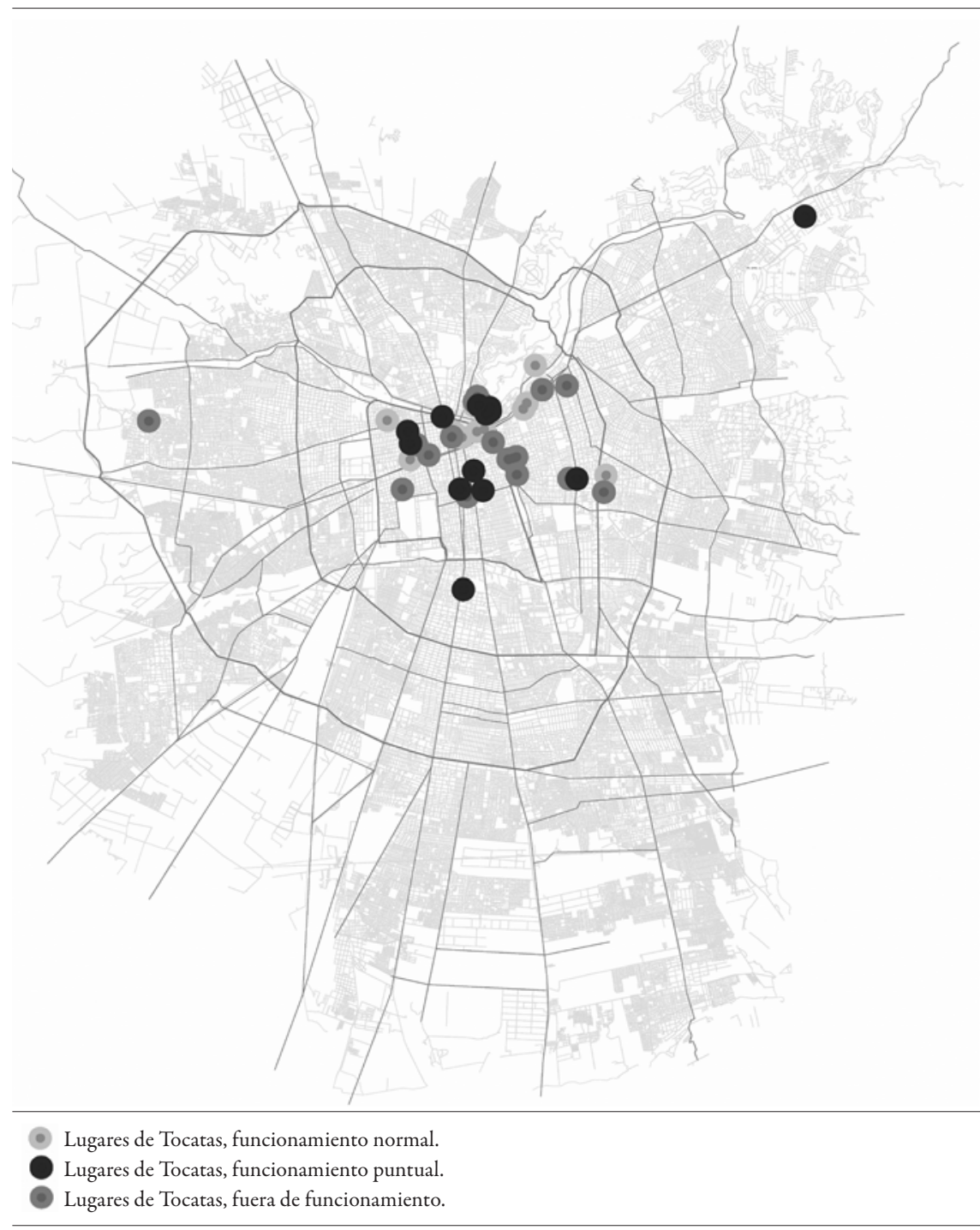

FUENTE ELABORACIÓN PROPIA.

Como lo muestra la Figura 2, la EME no ha creado "fijezas espaciales". La escena reporta haber utilizado 45 locales para música en vivo entre 2004 y 2007. De éstos, 19 no están en funcionamiento y 12 son sólo ocasionalmente utilizados (menos de 2 veces en un período de 12 meses). Y de los 14 locales en uso actual al momento de la investigación, sólo 2 habían estado en funcionamiento por más de un año. Y de estos dos locales, sólo Bar Uno - un pequeño y precario local en Bellavista- es considerado como un espacio dedicado exclusivamente a la EME. 
Sin embargo, al momento de la investigación Bar Uno había perdido su prominencia. Por una parte el local estaba siendo remodelado, pero, por la otra, y más significativamente, Ervo Pérez, cabeza de Productora Mutante, un agente clave en la organización de la escena y el contacto entre Bar Uno y la escena, se encontraba fuera del país. En otras palabras, la existencia de la EME pendía de las capacidades emprendedoras de un único individuo.

Esto nos lleva a otra dimensión de la naturaleza móvil de la escena: no es sólo que los espacios de la escena estén en constante movimiento sino, también, que las lógicas de la escena están caracterizadas por la contingencia y la temporalidad. O dicho de otra manera, la geografía de la EME es inherentemente eventual: sin ningún tipo de soporte financiero, espacial o institucional, la escena depende del siempre cambiante e impredecible flujo de eventos que, incluso para los miembros de la escena, parecen siempre fuera de control. Rodrigo de Olaüs Romer lo dice explícitamente: "He tratado de organizar [tocatas], pero no sé por qué tengo mala suerte. Por ejemplo, he organizado tocatas donde está todo listo, tengo los posters impresos y de repente el local se baja". No hay pivotes organizacionales (o institucionales) sustanciales a los cuales recurrir en caso de imprevistos, por lo que la escena es el resultado de la conjunción de una variedad de contingencias que son "pegoteadas" sólo por un momento específico y todo puede siempre ser, hasta el último minuto, diferente. Nelson de Neurotransmisor pone un ejemplo en relación a la práctica -clave en la escena- de buscar un local para tocatas. Revisando la historia de presentaciones en vivo de la banda, Nelson recuerda que una presentación se realizó en Cerrillos, en "un local bien conocido que casi siempre lo prestaban sin cobrar. Después tocamos en Casa Usher, sólo porque ahí también ensayábamos. La otra tocata fue porque un amigo vio un local, le gustó y habló con el dueño para hacer algo ahí". Se extrae de las palabras de Nelson que las presentaciones de Neurotransmisor han sido casi anomalías, imposibilidades, excepciones fortuitas que, de alguna manera siempre casual, se han materializado.

La teoría de los clusters creativos ha asumido como válida la idea según la cual los agentes creativos viven y trabajan en el mismo sector. Este solapamiento sería uno de los pilares del cluster. Pero como ya se vio, los espacios de ejecución no calzan con los de producción. Y ahora podemos agregar un elemento adicional que cuestiona el supuesto del live \& work: los integrantes de la EME tienen historias y cotidianidades productivas marcadas más por el nomadismo y el recorrido que por el asentamiento. En efecto, la Figura 3 muestra cuál ha sido la historia (y la localización) de las salas de ensayos de la EME. De los 16 proyectos cuyas historias pudieron ser reconstruidas, la mitad ha cambiando en 4 o más oportunidades de sala de ensayo, y en total trece lo han hecho 3 o más veces. En promedio, los proyectos de la EME han cambiado de sala de ensayos 3,5 veces durante su historia. Si la antigüedad promedio de los proyectos es de 2,5 años, entonces tenemos que los miembros de la escena cambian de sala de ensayo cada 8 meses y que éstas, como se ve en las cartografías, no siempre mantienen su área de localización. 
FIGURA 3 | Historia geográfica de espacios de producción

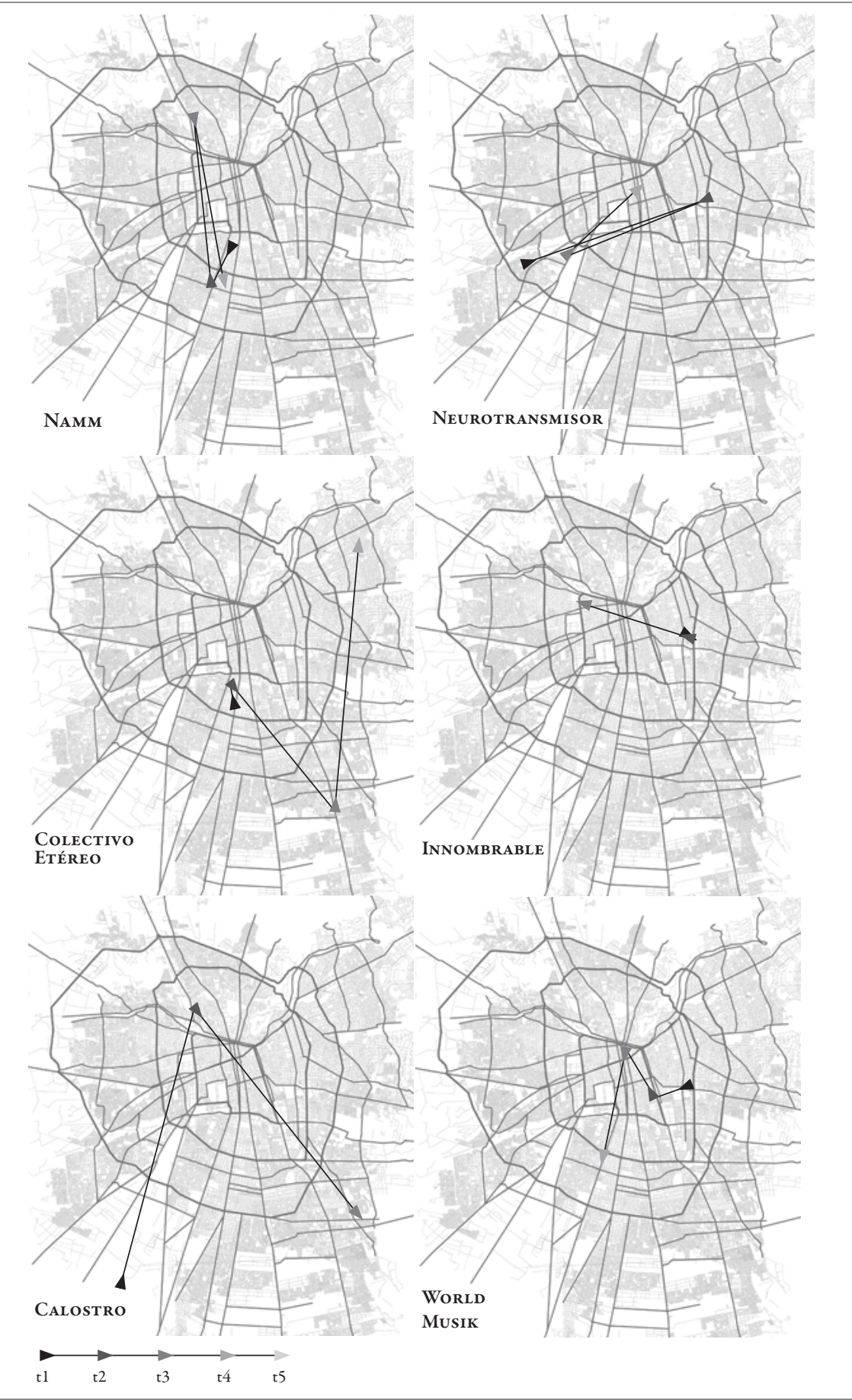

FUENTE ELABORACIÓN PROPIA. 
Por su parte, la Figura 4 muestra los recorridos que cinco miembros de la EME realizaron durante una semana. Lo que resalta es que nos enfrentamos a rutinas largas de movilidad. Del total de viajes realizados por los cinco entrevistados ( 58 trayectos), el 76\% son de más de 2,5 kilómetros. Además, los movimientos no están estructurados en torno a un centro pivotal único. Por el contrario, éstos se ordenan de manera expandida y con centros gravitacionales distribuidos.

\section{FIGURA 4 | Movilidad cotidiana de la EME}

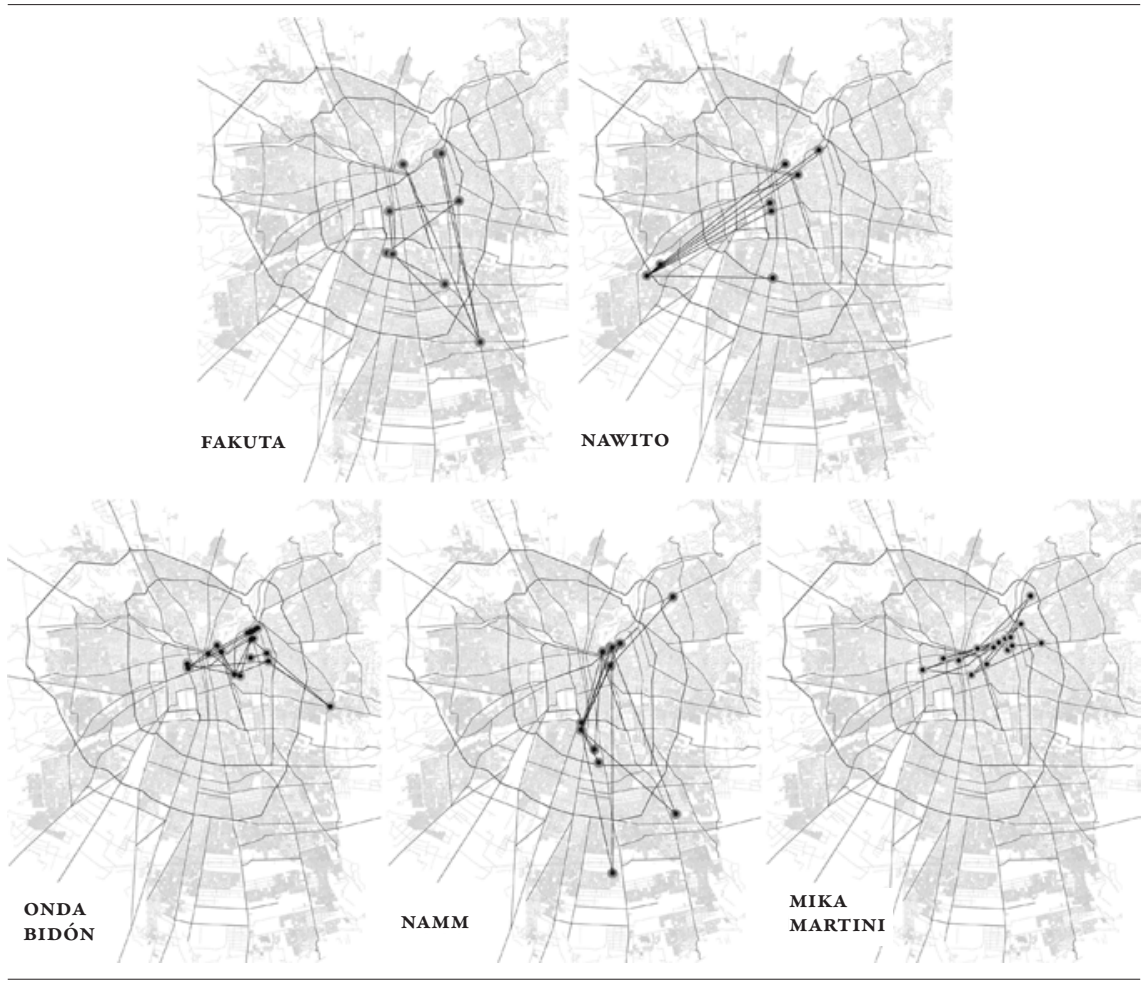

FUENTE ELABORACIÓN PROPIA.

En definitiva, tenemos que la cotidianidad de la EME (y su historia locacional) está marcada por el traslado: es una cotidianidad "en tránsito" en la cual la experiencia del movimiento -y del movimiento multifocal y extensivo- está en su núcleo.

\section{Identidades porosas}

Ante este escenario, ¿cómo puede la EME eludir la fragmentación y la disolución y, finalmente, encontrar continuidad? La respuesta hay que buscarla en las prácticas propias de los actores y en las tácticas que despliegan. Y al analizar la EME es posible reconocer que del mismo modo en que su geografía es múltiple, las unidades de esta industria no son unitarias. De hecho, los agentes de la escena no son propiamente "bandas" sino proyectos: los agentes económicos de la EME, más que 
unidades autocontenidas, duraderas e institucionalmente incrustadas -el tipo de agente usualmente asumido por la teoría de los clusters- son actores-red transitorios, orientados a la tarea y ajustables al entorno (Boltanski y Chiapello, 1999; DeFillipi y Arthur, 1998; Grabher, 2001, 2002a y 2002b).

Un hecho que define esta naturaleza líquida de los proyectos de la escena es su identidad porosa. La teoría de los clusters asume que las firmas tienen identidades fijas y diferenciables en términos funcionales y dimensionales (Marshall, 1881). Este supuesto, sin embargo, no aplica para la EME, en la cual la identidad de sus "firmas" está siendo continuamente construida y negociada.

Efectivamente, los proyectos de la EME son entidades que admiten más de una identidad productiva y estética. Primero, los miembros de la escena participan en más de un proyecto, por lo que los bordes entre uno y otro son altamente permeables. Reflexionando sobre la efervescencia de la escena, Walter de Congelador -uno de los proyectos más antiguos de la EME-, dice:

Algo que ha ayudado [a la emergencia de bandas] es esa capacidad de desdoblarse tantas veces [que tienen los más jóvenes], que yo en verdad no la tengo. Como que con este loco el proyecto se llama tanto, y grabamos una huea, y mi proyecto solista se llama tanto y al final los hueones terminan como con 5 grupos diferentes, o 6 grupos, no sé.

Un incentivo importante para esta rápida incubación de proyectos ha sido el incrementado acceso a tecnologías de bajo costo. La llegada del computador como instrumento musical fue liberatoria y permitió la multiplicación de los proyectos. Hablando sobre los orígenes de Namm, Pablo dice:

El 2003 [empezamos] a probar otras cosas, sobre todo porque el Sebastián tenía un computador en esa época y él conocía un poco más de software, y ahí empezamos a grabar. Después me regalaron uno y empezamos a grabar cosas en mi casa, o en su casa, y empezamos a grabar esos registros, a improvisar, a grabar encima, a hacer pistas. Ahí nos dimos cuenta de que se podía hacer música sin tener una banda, que a veces era mucho más práctico el computador.

Adicionalmente, las redes sociales on-line con aplicaciones de streaming como Myspace, ampliamente utilizadas por la EME, minimizaron los costos de producción y distribución. Así, sin mayores barreras tecnológicas y/o materiales de acceso, las posibilidades de formar una "banda" se multiplicaron. "Hicimos como un pijama party [con Dadalu] y nos fumamos un pito y estábamos voladas y empezamos a grabar cosas. Eso es World Musik. Y no sé, a la gente le gustó”, recuerda Fakuta (de Banco Mundial) sobre los espontáneos orígenes de World Musik, su proyecto paralelo con Dadalu, también de Julia Rose, Colectivo Etéreo e Iris. El resultado es una compleja y entreverada ecología de fusiones, alianzas y colaboraciones temporales en las cuales las fronteras de cada proyecto son continuamente redefinidas. Es decir, lo que cuenta como "proyecto" o "banda" es el efecto performativo de una asociación momentánea que se ha consolidado en un agente unitario (White, 1992; ver también Sheller, 2004). 


\section{Multifuncionalidad}

La porosidad de la escena también remite a la multifuncionalidad de sus agentes. Más que desplegar una división del trabajo especializada, cada actor de la EME ha internalizado las funciones necesarias para la reproducción del sistema. No hay "bandas" por un lado y "promotores", "técnico" y "diseñadores" por el otro: para existir, los miembros de la escena han dislocado su identidad para desempeñar múltiples tareas. Pablo Flores, además de su trabajo en Namm, dirige Jacobino Discos y opera como organizador de eventos; Ervo Pérez, miembro de DiAblo, Colectivo NO, Fake Daddy y La Golden Acapulco, es también la cabeza de Productora Mutante, una organización que promueve proyectos noise y organiza tocatas y festivales; Héctor, también conocido como Asa de Lippes y miembro de Mega Toy, dirige Cumshot Records, netlabel y oficina semiformal de servicios audiovisuales; Rodrigo de Olaüs Romer y Montaña Extendida diseña varios de los posters y flyers de la escena, lo mismo que Diego de La Banda's; Mika Martini dirige el netlabel Pueblo Nuevo; Carlos de Mostro y Come Perro Fuma Gato hace el arte para varios proyectos y dirige el netlabel Horrible Registros; Daniel de DiAblo, Colectivo No y La Golden Acapulco, junto a Nicolás, de Innombrable, son ingenieros en sonido y han grabado a varias bandas de la escena.

FIGURA 5 | Identidades porosas en la EME: el caso de Fakuta, Nawito y Dadalu

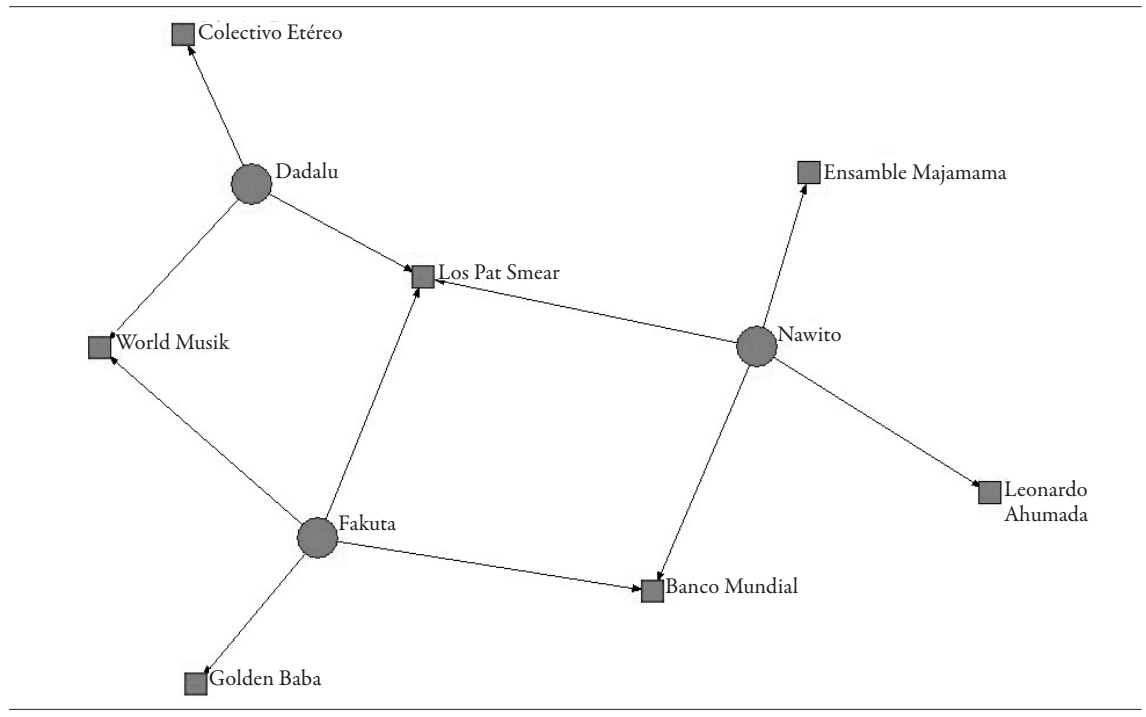

FUENTE ELABORACIÓN PROPIA.

La capacidad emprendedora de los agentes culturales no es nueva (Lloyd, 2004 y 2006), como tampoco la ideología del "Do It Yourself" inaugurada por el punk y consolidada como parte del ethos de las vanguardias desde entonces. Sin embargo, esas aproximaciones han sido siempre realizadas en el marco de un milieu creativo 
en el cual la colaboración y cooperación son parte fundamental de una disposición estética más amplia y referidas a la posición relativa del artista en el campo cultural (Bourdieu, 1993; Lloyd, 2006). En la EME, por el contrario, este impulso es táctico: es un medio de sobrevivencia de cara a un entorno altamente precario. Pablo, de Namm y director de Jacobino Discos se refiere a esta situación directamente: "Hacer una tocata es mandar mails, hablar con gente, hablar con los medios, poner avisos, diseñar un buen cartel, cortar entradas. A mí me cuesta estar cortando entradas, pero lo hago igual".

\section{"Estar ahi" virtual}

En suma, los proyectos no son entidades estables. Más bien, lo contrario, actualizan una identidad amébica cuyos límites están siendo constantemente redefinidos, al igual que el territorio que ocupan. Pero la EME se las ha arreglado para construir su propio "estar ahí" a través de MySpace.

MySpace es una red social que permite la reproducción, el streaming y la descarga de archivos de audio. Estas capacidades han hecho de MySpace el medio de comunicación online preferido de las escenas musicales locales en Chile y otras partes del mundo (Noble, 2008). En la EME, MySpace está entreverado en tantas y tan diversas formas con las prácticas productivas de la escena que es imposible separar el uno del otro. MySpace es donde se ejecutan las relaciones horizontales de la escena: es donde se despliegan las posibilidades de competición e imitación. Por ejemplo, Nicolás de Innombrable dice:

De los 8 temas del disco, 6 están ahí para que se puedan descargar. En ese sentido, están todas las cosas para que esté todo el material disponible para todos, o sea yo también en mi casa me pongo a dar vueltas en MySpace para escuchar música nueva, ver con qué gente están tocando otras personas y encuentras de todo po.

Darse una vuelta por Myspace: el sitio se ha convertido en el lugar de lo público para la EME. En ausencia de un medium territorial en el cual se incrusten los proyectos y al cual los agentes puedan recurrir para cartografiar la producción de la escena y sus innovaciones, MySpace ha emergido como esa ágora. Pero no se trata sólo de un reemplazo: Myspace se ha convertido en una condición de posibilidad para la EME. Si no tienes una cuenta en MySpace "no tienes segundas opiniones", dice Calostro, "y es eso lo que te genera el estatus de banda". En otras palabras, para ser una banda debes estar disponible en el espacio público, y ese espacio para la EME no es un barrio bohemio o un distrito creativo, sino el territorio distribuido y virtual de Internet. La EME demuestra que el "estar ahí" existe, y que de hecho se nutre de la copresencia, pero que esta copresencialidad puede construirse de muy variadas formas, incluso gracias a la mediación no-humana. 


\section{Conclusiones}

Entonces, ¿cómo es la especialidad de la EME? Los resultados anteriormente reseñados pueden ser resumidos en siete constataciones:

- La EME no tiene una espacialidad sino varias. La EME no está constituida por un espacio único sino por una red que ensambla múltiples espacios. Específicamente, se identificaron tres tipos de espacios, cada uno con sus propias lógicas urbanísticas: los espacios de ejecución, socialización y producción.

- Las tres espacialidades de la EME no confluyen. Existen solapamientos e interfaces, pero no alineamientos. En definitiva, la EME no tiene una espacialidad unitaria -bajo la forma, por ejemplo, de un barrio, distrito o cluster- sino distribuida.

- Los espacios de la escena son móviles. La espacialidad de la EME no sólo es múltiple, sino también nómada: no está fija en el territorio. Las prácticas de la EME están marcadas por geografías extensivas y, por ende, ancladas en la experiencia del trayecto: la EME se construye espacialmente moviéndose de un lugar a otro de la ciudad sin solución de continuidad.

- Los espacios de la escena son eventuales. La espacialidad de la EME no sólo está sustentada en la movilidad. Sus espacios, además, nacen, mueren y se transforman eventualmente, dependiendo de los acontecimientos y situaciones contextuales que tenga que enfrentar.

- La escena se organiza de manera contingente. Ante la precariedad institucional y económica de la escena y su espacialidad múltiple y móvil, la estructura organizativa de la escena es, concordantemente, líquida y contingente: se actualiza -y desaparece- una y otra vez en función de las circunstancias.

- Los agentes de la escena son porosos y cambiantes. A su vez, los propios actores de la escena tienen bordes maleables. Los "proyectos" son entidades en constante mutación y los actores de la escena actualizan diferentes funciones sin perder nunca su coherencia identitaria.

De estos resultados pueden extraerse al menos tres conclusiones. En primer lugar, estamos ante una economía localizada que no cumple con ninguno de los presupuestos espaciales de la teoría de clusters. La EME se despliega en un espacio, pero éste no es ni delimitado, ni fijo, ni está -como sería esperable para un cluster creativourbanísticamente conformado. Por el contrario, estamos ante una ecología productiva que se desenvuelve en una espacialidad múltiple, cambiante, extendida, virtual y contingente. Pero esto, y esta es la segunda conclusión, no impide que la EME logre estabilidad y, más aún, una performance propia de un cluster. La espacialidad de la EME, tan distinta a la que se espera de un cluster, no ha minado la capacidad innovadora y creativa de esta industria.

La pregunta fundamental es cómo la EME ha logrado sortear con éxito esta contradicción. La tercera conclusión, así, es que la respuesta está en la capacidad de la EME para crear una referencia mutable. 
En efecto, sin recursos económicos, con nulo apoyo institucional, propulsada por agentes sin una identidad fija y marcada por la precariedad material, el panorama esperable para la EME es colapsar en manos de la inestabilidad total. La única posibilidad de la EME para superar esta inestabilidad, siguiendo las perspectivas tradicionales, es encontrar un punto de referencia que dote a la escena de la fijeza y estructuración que necesita. Uno de esos puntos de referencia para los clusters en general, y tal vez el más importante para los clusters creativos en particular, es el territorio con todas las características que ya se han descrito. Pero esa posibilidad no está disponible para la EME. O mejor dicho, esa posibilidad no es funcional para las características productivas, culturales y territoriales de la EME. La escena tiene que buscar otro modo de ordenarse y estabilizarse, otro modo de encontrar coherencia y unidad y de desarrollar todos los elementos propios de un cluster. Y esto no lo hace echando mano a un macroestabilizador (como podría ser un barrio) sino desarrollando una continuidad de microestabilidades transitorias y eventuales que es fruto de las prácticas de los propios agentes de la escena. O puesto de otra forma: ante un entorno hostil y una condición altamente precaria, la clave de la sobrevivencia no está en generar grandes fijezas, sino en la capacidad para ir construyéndolas adaptativa y momentáneamente de acuerdo a las especificidades de cada situación o evento.

La clave está en lo que parafraseando a Law (2002) se podría llamar una espacialidad fluida: en un espacio en el cual, para lidiar con la volatilidad y el riesgo, sus elementos no se mantienen inmóviles sino, todo lo contrario, cambian. Es más. Siguiendo a White (1992), se podría decir que lo que hace la EME para sobrevivir no es sólo lograr una estabilidad sustentada en la mutabilidad, sino que también en el acople/desacople: en la EME los elementos no sólo van cambiando de acuerdo a las circunstancias sino que, más profundamente, éstos aparecen y desaparecen, se ensamblan y desensamblan en función de los eventos. Esto es lo que hace la EME: no existe nada prefigurado ni preexistente; las piezas para armar una tocata (conseguirse un local, diseñar un afiche, asegurar equipamientos) se ensamblan para cada evento disolviéndose cuando éste acaba; los proyectos existen un día y al otro dejan de hacerlo, o se fusionan, o se bifurcan; si no hay un espacio colectivo, la escena se vuelca al territorio distribuido y virtual de internet; los miembros de la escena son intercambiable y circunstancialmente músicos, técnicos de grabación o porteros en locales; los proyectos son, en definitiva, tan flexibles como el milieu que los acoge y eso les permite moverse (y producir) sin colapsar.

Aquí empiezan a delinearse los contornos para la formulación de una alternativa a la espacialidad convencional asumida en la teoría de clusters y de la ciudad creativa. White (1992) llama "gel" a aquellas estructuras en las cuales sus agentes y elementos pueden acoplarse y desacoplarse sin perder unidad y consistencia. White prefiere hablar de gel que de red, concepto tan caro para sociólogos y geógrafos, puesto que éste último es demasiado rígido para dar cuenta de situaciones, como las aquí descritas, en las que el foco de referencia está en constante cambio. Siguiendo a White, se podría decir que la EME presenta una nueva forma de entender la es- 
pacialidad de las economías clusterizadas, una forma que podría denominarse una espacialidad gel: una espacialidad que no presupone constancias, delimitaciones o escalas sino que se va constituyendo eventualmente, ensamblando -sólo temporalmente- los elementos que la conforman.

Esto no significa que el espacio morfológico y la ciudad hayan perdido relevancia en la constitución de economías localizadas. Todo lo contrario, lo que aquí se postula es que ese espacio tan relevante es enactado ${ }^{2}$, a través de las prácticas y tácticas de sus agentes, de manera fluida, dinámica y eventual sin necesidad de contar con un macrorreferente (espacial) que ordene la actividad productiva. Más bien lo opuesto, lo que aquí se defiende es que es sólo gracias a una estructura espacial mutable, móvil y temporal -o lo que aquí se ha denominado geografía gel- que la EME puede sobrevivir a un entorno económico, institucional y urbano tan precario y hostil. Creemos, por lo mismo, que esta manera de aproximarse a la geografía de los clusters en general, y a los creativos en particular, es especialmente útil en ciudades en vías de desarrollo donde no se encuentran las características urbanas -aplicable sólo para casos muy específicos de Europa y Norteamérica- que la teoría de clusters supone. IEURE emerge relacionalmente y en la práctica (Mol, 2002; Ossandón, 2008). 


\section{Referencias bibliográficas}

Agnew, A. (1987). The United States in the World Economy. Cambridge: Cambridge University Press.

Amin, A. (2000). Spatialities of globalization. Environment and Planning A 34 (pp. 385-399).

Amin, A. \& Cohendet, P. (2004). Architectures of knowledge; firms, capabilities, and communities. Oxford: Oxford University Press.

Amin, A. \& Thrift, N. (2002). Cities, Reimagining the Urban. Londres: Polity Press.

Aydalot, P. (1986). Milieux Innovateurs en Europe. Paris: GREMI.

Audretsch, D. \& Feldman, M. (2003). Knowledge Spillovers and the Geography of Innovation. En J. Vernon \& J. Thisse (Eds.). Handbook of Urban and Regional Economics, Vol 4. Amsterdam: North Holland Publishing.

Bathelt, H., Malmberg, A. \& Maskell, P. (2004). Clusters and knowledge: local buzz, global pipelines and the process of knowledge creation. Progress in Human Geography 28 (pp. 31-56).

Becattini, G. (2002). Del distrito industrial marshalliano a la "teoría de distrito" contemporánea. Una breve reconstrucción histórica. Investigaciones Regionales, Otoño, No. 001.

Boltanski, L. \& Chiapello, E. (1999). The New Spirit of Capitalism, New York: Verso.

Bourdieu, P. (1993). The field of cultural production, New York: Columbia University Press.

Brown, J.S. \& Duguid, P. (1991). Organizational learning and communities of practice: toward a unified view of working, learning, and innovation. Organization Science 2 (pp. 40-57).

Callon, M. (1986). Some Elements of a Sociology of Translation: Domestication of the Scallops and the Fishermen of Saint Brieuc Bay. En J. Law (Ed.). Power, Action and Belief: a new Sociology of Knowledge? Londres: Routledge and Kegan Paul.

Camagni, R. (2005). Economía Urbana. Barcelona: Boch-Ico.

Camagni, R. \& Maillat, D. (2006). Milieux innovateurs. Théorie et politiques. Paris: Economica-Anthropos.

Carew, A. (2006). Sounds of'06: Nicest surprise'. The Age, 29 December, http://www.theage.com.au/ news/music/the-sounds-of-06/2006/12/28/1166895393620.html?page=fullpage

Castells, M. (1979 [1970]). La Cuestión Urbana. Madrid: Siglo XXI.

Catungal, J., Leslie, D. \& Hii, Y (2009). Geographies of Displacement in the Creative City: The Case of Liberty Village, Toronto. Urban Studies 46(5-6) (pp. 1095-1114).

Crewe, L. (1996). Material culture: embedded firms, organisational linkages and the local economic development of a fashion quarter. Regional Studies 30(3) (pp. 257-272).

Crew, L. \& Beaverstock, J. (1998). Fashioning the city: cultures of consumption in contemporary urban spaces. Geoforum 29 (pp. 287-308).

Cunha, M. \& Aricó, R. (2001). La formación de un cluster en torno al turismo de naturaleza sustentable en Bonito, Brasil. CEPAL, Serie Desarrollo Productivo No 83.

DeFillippi, R. \& Arthur, M. (1998). Paradox in project based enterprise: the case of filmmaking. California Management Review 40(2), (pp. 125-39).

Deutshe, R. \& Ryan, C. (1989). The fine art of gentrification. October 31 (pp. 91-111).

Donald, B. \& Morrow, D. (2003). Competing for Talent: implications for social and cultural policy in Canadian city-regions. Report prepared for Strategic Research and Analysis (SRA) Strategic Planning and Policy Coordination, Department of Canadian Heritage.

Du Gay, P. (Ed.) (1998). Production of Culture/Cultures of Production. Londres: Sage Publications. 
Du Gay, P. \& Pryke, M. (Eds.) (2002). Cultural Economy: Cultural Analysis and Commercial Life. Londres: Sage Publications.

Featherstone, M. (1991). Consumer culture and postmodernism. Londres y Newbury Park: Sage.

Fernández, V. (Ed.) (2008). Clusters y desarrollo regional en América Latina. Reconsideraciones teóricas y metodológicas a partir de la experiencia argentina. Buenos Aires: Miño y Dávila Editores.

Fernández, V. \& Vigil, J. (2007). Clusters y desarrollo territorial: revisión teórica y desafíos metodológicos para América Latina. Economía, sociedad y territorio 7(24) (pp. 859-912).

Florida, R. (2002). The Rise of the Creative Class: And How It's Transforming Work, Leisure, Community and Everyday Life. New York: Basic Books.

Florida, R. (2005). Cities and the Creative Class. New York: Routledge.

Fougère, M. \& Solitander, N. (2007). The Rise of Creative Governmentality -And how it's transgressing working hours, job security, politics and everyday strife. Fifth International Critical Management Studies Conference. Manchester: Manchester University.

Gago, A., De la Torre, D., Picón, M., Delamarre, R. \& Tinto, C. (2007). Competitividad productiva y sustitución de importaciones en las industrias ligadas a las cadenas productivas agroalimentarias en la Región de Cuyo-Argentina. Kairos: Revista de temas sociales 19 (pp. 1-14).

Gertler, M. (2003). Tacit knowledge and the economic geography of context, or the undefinable tacitness of being (there). Journal of Economic Geography 3 (pp. 75-99).

Giuliani, E. and Bell, M. (2004). When Micro Shapes the Meso: Learning Networks in a Chilean Wine Cluster. SPRU Electronic Working Paper Series. Sussex: University of Sussex.

Glaeser, E. (2004). Review of Richard Florida's The rise of the creative class. Disponible en http://www. creativeclass.org/

Grabher, G. (2001). Ecologies of creativity: the Village, the Group, and the heterarchic organisation of the British advertising industry. Environment and Planning A 33 (pp. 35-374).

Grabher, G. (2002a). The project ecology of advertising: tasks, talents and teams. Regional Studies, 36 (pp. 245-263).

Grabher, G. (2002b). Cool projects, boring institutions: temporary collaboration in social context. Regional Studies 36 (pp. 205-214).

Harvey, D. (1973). Social Justice and the City. Baltimore: The Johns Hopkins University Press.

Healy, K. (2002). What's New for Culture in the New Economy. Journal of Arts Management, Law, and Society 32(2).

Hirsch, W. (1973). Urban Economic Analysis. New York: McGraw-Hill.

Hutton, T. (2006). Spatiality, built form, and creative industry development in the inner city. Environment and Planning A 38 (pp. 1819-1841).

Ibert, O. (2010). Relational distance: sociocultural and time-spatial tensions in innovation practices. Environment and Planning A 42 (pp. 187-204).

Indergaard, M. (2003). The Webs They Weave: Malaysia's Multimedia Super-corridor and New York City's Silicon Alley. Urban Studies 40 (pp. 379-401).

Indergaard, M. (2003). What to Make of New York's New Economy? The Politics of the Creative Field. Urban Studies 46(5-6) (pp. 1063-1093).

Jackson, P. y Thrift, N. (1995). Geographies of Consumption. En D. Miller (ed.), Acknowledging Consumption: A Review of New Studies. Londres: Routledge.

Jacobs, J. (1968 [1992]). The death and life of great American cities. New York: Vintage. 
Jiron, P. (2009). Prácticas de movilidad cotidiana urbana: un análisis para revelar desigualdades en la ciudad. En M. Tironi \& F. Pérez (Eds.), SCL: espacios prácticas y cultura urbana. Santiago: ARQ Ediciones.

Kern, H. (1996). Vertrauensverlust und blindes Vertrauen: Integrationsprobleme im ökonomischen Handeln. Göttingen: SOFI-Mitteilungen.

Knorr Cetina, K. (1999). Epistemic Cultures: How the Sciences Make Knowledge. Cambridge, MA: Harvard University Press.

Krugman, P. (1991). Geography and Trade. Cambridge, MA: MIT Press.

Latham, A. \& McCormack, D. (2009). Globalizations Big and Small: Notes on Urban Studies, Actornetwork Theory, and Geographical Scale. En I. Farias \& T. Bender (Eds.). Urban Assemblages. How Actor-Network Theory Changes Urban Studies. Londres y New York: Routledge.

Law, J. (2000). Objects, Spaces and Others. Centre for Science Studies, Lancaster University, http:// www.comp.lancs.ac.uk/sociology/papers/Law-Objects-Spaces-Others.pdf

Law, J (2002). Objects and Spaces. Theory, Culture and Society 19 (pp. 91-105).

Law, J. \& Hetherington, K. (2000). Materialities, Spatialities, Globalities. En J. R. Bryson, P. W. Daniels, N. Henry \& J. Pollard (Eds.). Knowledge, Space, Economy. Londres: Routledge.

Lefebvre, H. (2003 [1970]). The Urban Revolution, Minneapolis: University of Minnesota Press.

Ley, D. (2003). Artists, Aestheticisation and the Field of Gentrification. Urban Studies 40 (pp. 2527 2544).

Lewis, N. \& Donald, B. (2010). A New Rubric for 'Creative City’ Potential in Canada’s Smaller Cities. Urban Studies 47(1) (pp. 29-54).

Lloyd, R. (2004). The neighborhood in cultural production: material and symbolic resources in the new bohemia. City and Community 3 (pp. 343-371).

Lloyd, R. (2006). Neo-Bohemia: Art and Commerce in the Postindustrial City. New York: Routledge.

Malberg, A. \& Maskell, P. (2002). The Elusive concept of localization economies: towards a knowledgebased theory of spatial clustering. Environment and Planning A, 34(3) (pp. 429-449).

Markusen, A. (2006). Urban Development and the Politics of a Creative Class: Evidence from the Study of Artists. Environment and Planning A 38(10) (pp. 1921-1940).

Marshall, A. ([1881] 2005). Principios de Economía. Madrid: Editorial Síntesis.

Maskell, P., Bathelt, H. \& Malmberg, A. (2004). Temporary Clusters and Knowledge Creation: The Effects of International Trade Fairs, Conventions and Other Professional Gatherings. Spaces 4.

Massey, D. (2005). For Space. Londres: Sage.

Mol, A. (2003). The Body Multiple. Ontology in medical practice. Durham \& London: Duke University Press.

Morandé, P. (1984). Cultura y Modernización en América Latina. Santiago de Chile: Cuadernos del Instituto de Sociología UC.

Moulaert, F. \& Sekia, F. (2003). Territorial Innovation Models: A Critical Survey. Regional Studies 37 (3) (pp. 289-302).

Muñoz, F. (2008). Urbanalización: paisajes comunes, lugares globales. Barcelona: Gustavo Gili.

Murdoch, J. (2006). Post-structuralist geography. A guide to relational space. Londres: Sage.

Noble, J. (2008). The power of mobile texting and the connecting of place in creating a cultural scene. ANZCA08 Conference, Power and Place. Wellington. 
O'Connor, J. (2004). 'A Special Kind of City Knowledge': Innovative clusters, tacit knowledge and the 'Creative City'. Media International Australia 112 (pp. 131-149).

Orlikowski, W. (2000). Using Technology and Constituting Structures: A Practice Lens for Studying Technology in Organizations. Organization Studies 11(4) (pp. 404-428).

Ossandón, J. (2008). The Enactment of Private Health Insurance in Chile. Tesis doctoral, Centre for Cultural Studies, Goldsmiths, University of London.

Owen-Smith, J. \& Powell, W.W. (2002). Knowledge networks in the Boston biotechnology community. Conference "Science as an Institution and the Institutions of Science". Siena, Universidad de Siena.

Peck, J. (2005). Banal urbanism: creativity as scalar narrative. Paper presented at the Studies in Political Economy conference, Toronto, York University.

Piore, M. \& Sabel, C. (1984). The Second Industrial Divide. New York: Basic Books.

Porter, M. (1998). Clusters and the new economics of competition. Harvard Business Review, November-December.

Ramos, J. (1998). Una estrategia de desarrollo a partir de los complejos productivos (clusters) en torno a los recursos naturales. Revista CEPAL, 66.

Ricardo, D. (1817 [2004]). Principles of Political Economy and Taxation. New York: Dover Publications.

Richardson, G.B. (1972). The Organisation of Industry. The Economic Journal 82(372).

Sabate, J. \& Tironi, M. (2008). Rankings, creatividad y urbanismo. EURE 34(102) (pp. 5-23).

Saxenian, A. (2006). The New Argonauts: Regional Advantage in a Global Economy. Cambridge, MA: Harvard University Press.

Sheller, M. (2004). Mobile publics: beyond the network perspective. Environment and Planning D 22 (pp. 39-52).

Silva, L. \& Simões, R. (2004). Oportunidades tecnológicas e produçao científica: uma análise microrregional para o Brasil. Eure, XXX (90), 85-102.

Slater, D. \& Ariztía, T. (2009). Assembling Asturias: Scaling Devices and Cultural Leverage. En I. Farias \& T. Bender (Eds.). Urban Assemblages. How Actor-Network Theory Changes Urban Studies. London y New York: Routledge.

Storper, M. \& Venables, A. (2004). Buzz: face-to-face contact and the urban economy. Journal of Economic Geography 4(4) (pp. 351-370).

Vásquez-Barquero, A. (2006). Surgimiento y transformación de clusters y milieus en los procesos de desarrollo. EURE 32(95) (pp. 75-93).

Tigre, P. \& Silveira, F. (eds.) (2009). Desafíos y oportunidades de la industria del software en América Latina. Bogotá: Cepal - Mayol Ediciones.

Tironi, M. (2009). Urbanismo creativo (en la ciudad performativa). Espacios y prácticas de la escena de música experimental en Santiago, Chile. Tesis de doctorado, Departamento de Urbanismo, Universitat Politècnica de Catalunya.

Tironi, M. (2009). Gelleable spaces, eventful geographies: the case of Santiago's experimental music scene. En I. Farias \& T. Bender (Eds.), Urban Assemblages. How Actor-Network Theory Changes Urban Studies. London y New York: Routledge.

Thrift, N. (1997). The still point: resistance, expressive embodiment and dance. En M. Keith \& S. Pile (Eds.), Geographies of Resistance. Londres: Routledge. 
Trullén, J. (2006). Producción y espacio urbano: algunos problemas económicos. Working Papers Departament d'Economia Aplicada Universitat Autònoma de Barcelona. Barcelona: Universitat Autònoma de Barcelona.

Von Thünen, J.H. (1826 [1966]). The Isolated State. New York: Pergamon.

Urry, J. (2000). Sociology beyond societies: mobilities for the twenty-first century. Londres: Routledge.

Uzzi, B. (1997). Social structure and competition in interfirm networks: the paradox of embeddedness. Administrative Science Quarterly 42 (pp. 35-67).

Waitt, G., y Gibson, C. (2009). Creative Small Cities: Rethinking the Creative Economy in Place. Urban Studies 46(5-6) (pp. 1223-1246).

Wenger, E. (1998). Communities of practice: learning, meaning, and identity. Cambridge: Cambridge University Press.

White, H. 1992. Identity and Control: A Structural Theory of Social Action. Princeton, NJ: Princeton University Press. 